Celestinesca 32 (2008): 291-305 https://doi.org/10.7203/Celestinesca.32.20119

\title{
Las tres primas del entorno celestinesco y una nota sobre el tema del linaje
}

\author{
Joseph T. Snow \\ Michigan State University
}

\section{Introducción}

La bibliografía existente sobre Elicia, Areúsa y Lucrecia - las tres primas en el entorno celestinesco- no es extensa, y sólo pocas veces se ha propuesto estudiarlas como grupo especial, que es lo que se propone aquí. Es más: pocas veces se enfoca en si su parentesco es de sangre o, como casi todos acuerdan, profesional. Y es que entre las que ejercían la prostitución, se sabe que la palabra "prima» se usaba como señal de reconocerse como camaradas de la misma profesión. En lo que sigue nos interesa analizar las posibles indicaciones textuales de una suerte de parentesco definitivo. Los resultados de esta búsqueda pueden sorprender. Primero, presento los datos que permiten conocer la historia personal - pasado y presente - de cada una de las tres. Segundo, será necesario rastrear el texto para el significado de las referencias usadas para vincularlas y lo haremos por parejas. Finalmente, habrá algunas conclusiones.

\section{Datos textuales de las tres primas: genealogía, edad y lugar}

Primero, Lucrecia. Esta joven ha tenido la buena fortuna -antes de iniciar la acción de la obra- de conseguir un empleo en una casa bien, la del rico burgués, Pleberio. Sirve a su mujer Alisa de criada, pero también es la constante acompañante de Melibea en todas sus apariciones textuales menos una: es en la primera escena que da inicio a la obra, en donde, digamos, brilla Lucrecia por su ausencia ${ }^{1}$. De Lucrecia, no sabemos nada,

1.- Como sólo hablan en la primera escena Calisto y Melibea, se supone que Lucrecia no está presente (el autor del argumento tampoco imagina la presencia de Lucrecia). Pero hay 
ni de su familia más inmediata ni de sus antepasados ${ }^{2}$, ni si nace en esta ciudad o si ha venido del campo como era el caso de tantas de las que se encuentran en servicio en las ciudades a finales del siglo quince. Queda sólo su nexo como "prima» de las dos prostitutas, Elicia y Areúsa, como lo señala Celestina en el auto IX (p. 234) .

¿Cuántos años tiene Lucrecia? Veamos. Cuando Lucrecia lleva un mensaje urgente de Melibea a la casa de Celestina en el tiempo del auto Ix y sólo piensa en comunicárselo con despacho nada más encontrarla, descubre con gran sorpresa, al entrar en esta casa conocida, a sus dos "primas» reunidas con dos compañeros y se refiere a este cuarteto -ingenuamente- como "tanta gente y tan honrada» (IX, p. 234). Ante esta sorpresa de Lucrecia, Celestina reacciona, detallando cómo antes era su casa ${ }^{4}$, «en mi prosperidad, hoy ha veynte años» cuando había «nueve moças de tus días, que la mayor no passava de deziocho años, y ninguna avía menor de quatorze» (p. 234). A base de estas palabras de Celestina, podemos suponer que tendría Lucrecia ahora entre los catorce y dieciocho años referidos.

Si la criada de Melibea no tiene más de dieciocho - y muy probablemente tiene menos - significa que entró como criada en la casa de Pleberio cuando tenía entre trece y quince años, una edad típica para estar ya en servicio ${ }^{5}$. Y hemos de suponer que, entrevistada por Alisa, la

otro acto en el que tampoco habla Lucrecia, pero que claramente está presente como espectador y oyente. Ocurre en el auto xxI, después del suicidio de Melibea, cuando su presencia es manifiesta por estas palabras de Pleberio a su mujer, Alisa: "¡Ay, ay, noble mujer, nuestro gozo en el pozo; nuestro bien todo es perdido; no queramos más bivir [...] ves allí a la que tu pariste y yo engendré, hecha pedazos. La causa supe della, más la he sabido por estenso de esta su triste sirviente» (p. 336, énfasis añadido). ¿Será tan descabellado suponer, entonces, la posibilidad de que Lucrecia estuviera presente - y callada - en la primera escena de la obra? En todo caso, es la única vez que vemos a Melibea en la obra no acompañada de su «leal criada y fiel secretaria» (x, p. 247), excepto cuando, entre los actos viII y IX, Melibea se queda encerrada sola en casa y manda que Lucrecia vaya urgentemente a la casa de Celestina para traerla sin demora. Además, Lucrecia conoce a Calisto desde antes y le reconoce la voz (XII, p. 259). Una de las posibilidades para justificar este conocimiento de voz es haberla oído antes ¿en la huerta? [La citación de las páginas se hace siguiendo la edición de D. S. Severin, Madrid, Cátedra, 1989; según se aclara en nota 3.]

2.- No descarto la posibilidad de que la abuela de Elicia fuera también abuela de Lucrecia y de Areúsa, como veremos abajo.

3.- Citaremos el texto por auto y página de la edición de D. S. Severin (Madrid, Cátedra, 1989).

4.- Celestina no se refiere aquí a ninguna casa física, sino a quienes componían sus habitantes hace veinte años. Aquella casa no puede ser la misma en la que esta conversación tiene lugar. Recordemos que la casa actual de Celestina es una que Lucrecia localiza sin que nadie tenga que decirle dónde está, sin estar ya tan cerca de la de Pleberio. Parece no ser la primera vez que entra en ella.

5.- Como señala A. Weber con claridad, en el siglo quince no era anormal que las chicas entraran en el servicio doméstico de niñas, muchas de ellas llegadas del campo ("Celestina and the Discourses of Servitude», in Negotiating Past and Present. Studies in Spanish Literature for Javier Herrero, ed. David T. Gies, Charlottesville, VA, Rockwood Press, 1997, pp. 127-144 [131]). Weber también nota que los autores de Celestina iban borrando el discurso de los sirvientes- 
joven Lucrecia, sin o con una acompañante presente (¿su madre?, ¿̇una tía?), vendría de una familia aceptable aunque pobre. Dado el estado y prestigio de Pleberio es evidente que, al contratar a Lucrecia, no se sabría de posibles vinculaciones con las familias de sus supuestas "primas», las dos prostitutas.

Sigamos unos pasos más: al inicio del auto IV, cuando ve Lucrecia a Celestina acercándose a la casa donde ella es fiel criada, se queda casi boquiabierta, porque hace tiempo que Celestina no había aparecido en estos «barrios no acostumbrados» (IV, p. 151), dando a entender que la criada sí recuerda la última vez que la había visto allí, cuando Celestina era vecina del barrio. Y ya no son "acostumbrados» estos barrios porque Celestina se mudó de casa y barrio hace unos dos años —o más-y desde aquel entonces no han sido visitadas Alisa y Melibea por su antigua vecina. Lucrecia se dirige a Celestina, llamándola «madre», y Celestina le responde, llamándola «hija». Estos saludos indican que se conocen ya, aun sin saber hace exactamente cuánto tiempo.

Hemos visto que Lucrecia sabe perfectamente (auto Ix) dónde vive Celestina después de su mudanza a otro barrio. Además las salidas acostumbradas de Celestina le son enteramente familiares a la criada de Alisa y se supone que desde hacía bastante tiempo se conocían para que esto sea plausible. Es evidente que conoce Lucrecia estas salidas de Celestina por haber formado parte de la casa de Pleberio cuando andaba haldeando la tercera por el barrio y frecuentaba esta casa. Lo confirma la exclamación de Lucrecia: "¿A esso sólo saliste de tu casa? Maravíllome de ti, que no es éssa tu costumbre, ni sueles dar passo sin provecho» (IV, p. 151). Además, Lucrecia tiene que saber que su "prima», Elicia, vive como ahijada en casa de Celestina, cuya historia de hechicera, vendedora de mozas, de yerbas, de solimán y de otras cosas, también la sabe perfectamente (IV, p. 152). Es bien evidente que el trato social de Celestina y Lucrecia, sirvienta en casa de Pleberio, no es nuevo y se conocieron bien antes aun del comienzo de la acción de la obra ${ }^{6}$.

Lucrecia, con sus diecisiete años, siendo fiel criada en la casa donde lleva unos años sirviendo, también es toda una mujer. Esto se ve cuando

como-niños (ejemplo de Pármeno en casa de Celestina), prefiriendo el discurso de los deseos de los sirvientes-como-adultos (p. 132). Prefiero no ver a Lucrecia en el servicio de PleberioAlisa-Melibea antes de los doce o trece años, de modo que si ahora tuviera unos diecisiete, llevaría no más de cuatro o cinco años como criada de la casa, y creo que su comportamiento y participación en los diálogos de la obra lo atestiguan.

6.- Lucrecia, sin ser nombrada, debería haber formado parte de esta casa de la cual Celestina misma hace alarde de frecuentar a menudo ante Calisto: "Quatro años fueron mis vezinas; tratava con ellas, hablava y reýa de día y noche; mejor me conoce su madre que a sus mismas manos, aunque Melibea se ha hecho grande, muger discreta, gentil» (VI, p.189). Es posible que Celestina exagere su familiaridad con Alisa para Calisto, pero su aprovechamiento de la ignorancia de los demás es algo que para ella funciona habitualmente. 
Celestina anuncia en el auto IX delante de todos los allí congregados, disculpando a Lucrecia su relativa inocencia:
Ábrela y entre ella y buenos años, que aun a ella algo se le entiende desto que aquí hablamos, aunque su mucho encerramiento le impide el gozo de su mocedad (p. 232, énfa- sis añadido).

Es virgen Lucrecia, pero no por ello totalmente inocente. Cuando la tercera le quería callar e intimidar en el auto IV, ofreciéndole lejía para enrubiar sus cabellos y unos polvos para quitarse olores de la boca, Lucrecia contesta sin titubear: "¡O, Dios te dé buena vejez, que más necesidad tenía de todo esso que de comer!» (p. 169). Claramente piensa en ponerse más atractiva anticipando la posibilidad de tener relaciones. En efecto, tiene sus ojos puestos en los nuevos sirvientes de Calisto, los que acompañan al amo en el mes de los amores que ella presencia desde una distancia discreta. Al escuchar los melindres de Melibea en el huerto, Lucrecia se dice: «Ya, ya, apaziguado es el ruydo; no ovieron menester despartidores; pero tanbién me lo haría yo si estos necios de sus criados me fablassen entre día, pero esperan que los tengo de yr a buscar» (XIX, 324, énfasis añadido). Y poco después, habiendo caído Calisto al ir a ayudar a estos mismos criados, Lucrecia quiere saber lo que pasó y pronuncia estas palabras: "Tristán, ¿Qué dizes, mi amor? ¿Qué es esso que llores tan sin mesura?» (XIx, 327, énfasis añadido) ${ }^{7}$.

Podemos concluir que Lucrecia, esta prima de Elicia (y de Areúsa), está a pocos pasos de también ser su "prima» de profesión.

Segundo, Elicia. Elicia vive y trabaja en la casa-prostíbulo de Celestina. Es la última de una larga línea de pupilas de Celestina, sucesora de esas «nueve moças» de antaño, pero no sabemos exactamente cuántos años son los que lleva ya en la casa de Celestina, aunque podemos conjeturar, como teoría, que estaba con ella antes de su traslado a la casa actual, hace - como recuerda Melibea - dos años (IV, p.158). Y si esta conjetura es plausible - y creo que es- viviría no muy lejos de donde trabajaba su prima, Lucrecia. ¿Cuántos años vivió Celestina -y algunos de ellos con Elicia como pupila- cerca de de la casa de Pleberio? Según la tercera, eran cuatro ${ }^{8}$.

7.- Si en el auto xix Lucrecia, escuchando desde los árboles del huerto a los embelesados amantes, muestra su frustración sexual («Mala landre me mate si más lo escucho; ¿vida es ésta? Que me esté deshaziendo de dentera y ella esquivándose por que la rueguen» [p. 324]), nos es lícito creer que, en el auto XIV, Lucrecia miente a su ama al contestar la pregunta de si los había oído, al contestarle así: «No, señora, que durmiendo he stado» (p. 287).

8.- Celestina: "Quatro años fueron mis vezinas; tratava con ellas, hablava y reýa de día y de noche; mejor me conoce su madre que a sus mismas manos, aunque Melibea se ha hecho grande, muger discreta, gentil» (vI, p. 189). No dudo que Celestina exagera la amistad con Alisa para ganar más favor con Calisto (su interlocutor), pero de lo que no podemos dudar es de que sí era vecina de ellas y los cuatro años son factibles. Aquí es cuando Sempronio oye 
De la familia de Elicia, el texto nos proporciona más información. El único pariente suyo que se menciona, fuera de su estado de ser "prima» de Areúsa y Lucrecia, es una abuela. Es insinuada esta abuela por Celestina en una conversación privada y rencorosa mantenida con Elicia, al final del auto VII. Un cliente había pasado por la casa, ausente Celestina, y Elicia le regaña a su «madre» por su tardanza ${ }^{9}$ y la tercera, molesta por esta reprimenda y la inactividad de Elicia, le regaña su impertinencia, diciendo:

¿Por qué tú no tomavas el aparejo y començavas a hazer algo? Pues en aquellas tales te avías de abezar y de provar, de quantas vezes me lo has visto hazer. Si no, aý te estarás toda tu vida, hecha bestia sin officio ni renta. [...] Hazíalo mejor quando tu abuela, que Dios haya, me mostrava este officio, que a cabo de un año sabía más que ella (pp. 209-210, énfasis añadido).

Pues, sin poder saber si era abuela paterna o materna, más de esta abuela no se puede decir ${ }^{10}$. Sin embargo, es sugerente especular que, si tanto la abuela como la nieta pertenecen a la misma profesión que Celestina, la madre de nuestra Elicia estaba no muy lejos de pertenecer a ella, y que Elicia habría heredado su profesión en un ambiente familiar, aunque entra a trabajar en ella sin la misma ambición o talante de su abuela y de su segunda «madre», Celestina ${ }^{11}$.

Claramente Celestina se muestra algo desilusionada con su pupila, y no es ésta la primera vez que ha hablado con ella en estos términos, intentando animarla a aprender nuevas cosas porque un día las va a necesitar, igual que Celestina las necesitó de Claudina, madre de Pármeno, y de la abuela de Elicia, para poder superar sus propios años de juventud

a Celestina usar el adjetivo "gentil», que luego le causará, repitiéndolo, tanto vituperio de las dos primas, Elicia y Areúsa, en el auto IX.

9.- Esta escena de la reprimenda de Elicia se repite al final del auto XI cuando se dirige a Celestina con estas palabras: «¿Cómo vienes tan tarde? No lo deves hazer, que eres vieja; tropeçarás donde caygas y mueras» (p. 254).

10.- Si la abuela de Elicia le instruía a Celestina — como joven prostituta — en sus primeros pasos de la alcahuetería, "permite inferir un viejo compradazgo entre la tercera y su propia familia» (Lida de Malkiel, La originalidad artística de La Celestina, Buenos Aires, EUDEBA, 1962, p. 643). Y esta familia tendría que incluir a Lucrecia, de quien es Elicia prima (rv, pp. 150-151), y Areúsa (vII, p. 204).

11.- Tal vez por el tono de reprimenda de Celestina, Elicia le contesta con una fuerza expresiva directa y enojada: «... ninguna ciencia es bienempleada en el que no la tiene afición. Yo le tengo a este officio odio; tú te mueres tras ello» (p. 210). Será un enfado efímero, sin embargo. Cuando Celestina está ya muerta, Elicia, desprovista y sin oficio, habla muy de otra manera de su ex-protectora (xv, pp. 300-301). 
en la prostitución y seguir ganado la vida como alcahueta, entre otros muchos oficio ${ }^{12}$.

Elicia es evidentemente atractiva e inteligente pero es también perezosa. Lleva unos años en un ahora muy venido a menos burdel de Celestina - probablemente, como creemos, desde antes de mudarse Celestina del barrio de Melibea. Por lo tanto, debe tener como mínimo unos veinte años e incluso unos pocos más. Mayor que Lucrecia, desde luego, tendrá Elicia más o menos los mismos años que su "prima», Areúsa ${ }^{13}$.

Encontramos en el primer auto, aún antes de conocerla, otra nota interesante sobre Elicia. Sempronio, hablando consigo mismo después de que Calisto le manda salir y dejarle solo, considera las posibilidades de obedecer (o no) a su amo: "Si le dexo, matarse ha; si entra allá, matarme há» (I, p. 89). Y en estas consideraciones de su muerte, entra Elicia: "Aunque por ál no deseasse bivir sino por ver [a] mi Elicia, me devería guardar de peligros» (p. 89, énfasis añadido). Esto indicaría que lleva ya cierto tiempo con ella como amiga y que en realidad la aprecia mucho. Y éste es un dato que más tarde reconoce Calisto, que recuerda a Sempronio sus propias y frecuentes alabanzas de Elicia: "Torpe cosa es mentirle el que enseña a otro, pues que tú te precias de loar a tu amiga Elicia» (I, p. 94, énfasis añadido). Calisto también conoce con quién anda Sempronio.

Tercero, Areúsa. Sabemos más de la familia de esta "prima». Desde el primer auto, sabemos por boca de Celestina que Areúsa es «hija de Eliso» (p. 124). Pármeno sí reconoce el nombre del padre (¿por qué?, podemos preguntarnos) y, como aprenderemos, ya ha intentado hablar varias veces con su hija, pero siempre sin éxito ${ }^{14}$. Menciona Areúsa a sus padres por primera vez en el auto VII, hablando del dolor de la madre que sufre: "No es sino mi mala dicha; maldición que mis padres me echaron, que no está ya por provar todo esto» (p. 204).

12.- Como una de las características destacadas del texto celestinesco es el uso de ironía, señalamos que dentro de unos días Elicia estará desprovista de «aquella que yo tenía por madre, aquella que me regalava, aquella que me encubría, aquella con quien yo me honrrava entre mis yguales...» (xv, p. 298). Pero como Celestina sabía, está Elicia sin recursos y, por eso, vendría a arrepentirse de su decisión de mantener su vida en la casa de Celestina, lamentando que su estado de soledad y pobreza («ni blanca ni presente veo entrar por mi puerta») y su caída mísera ("no me viera agora entre dos paredes sola, que de asco ya no ay quien me vea») la deprimen (XvII, p. 307).

13.- Se puede deducir que Lucrecia tiene menos años que sus primas por pensar en ellas como "gente honrada» en el auto Ix. Se puede especular también que el haber topado con una escena sensual en la que figuran personas conocidas ayuda a efectuar su olvido del mensaje urgente para Celestina. Fácilmente se ciega a su misión central y urgente.

14.- Revela Pármeno a Celestina que había fracasado en sus intentos de acercarse a Areúsa: "Yo ya desconfiava de la poder alcançar, porque jamás podía acabar con ella que me esperasse a poderle dezir una palabra» (vII, p. 200). Areúsa confesará a Celestina que nunca admitió los avances de Pármeno: "Que no le conozco; siempre ove vergüença dél» (vir, p. 206). Pocos han señalado estas relaciones previas entre Pármeno y Areúsa, de cuya unión sexual es Celestina el artífice, anticipando la de Calisto con Melibea. 
Más tarde Areúsa, increpando a Centurio, trae a colación de nuevo a sus padres, cuando jura en sus nombres:

Salta luego de aý, no te vea yo más; no me hables ni digas que me conoces; sino por los huessos del padre que me hizo y de la madre que me parió, yo te haga dar mis palos en esas spaldas de molinero, que ya sabes que tengo quien lo sepa hazer, y hecho, salirse con ello (xV, p. 295, énfasis añadido).

Aquí Areúsa no especifica el nombre (Eliso) de su padre, ni revela el nombre de su madre. Poco después, hablando con Elicia de los culpables, Calisto y Melibea, tampoco pondrá nombre a su madre, aunque sí la identificará por su profesión

Déxame tú, si yo les caygo en el rastro, quándo se veen, y cómo, por dónde, y a qué hora, no me hayas tú por hija de la pastellera vieja, que bien conociste, que si no hago que les amarguen los amores (XV, p. 299, énfasis añadido).

Efectivamente, si podemos conjeturar un parentesco de primas de sangre entre Areúsa y Elicia, esta pastellera vieja ${ }^{15}$, ahora muerta, y tan bien conocida a Elicia, habría sido su tía. Es evidente que Areúsa recuerda con gran admiración a su madre, en cuya figura está jurando tomar su venganza sobre Calisto y Melibea.

¿Cuántos años tendrá Areúsa? Esta bellísima mujer con un cuerpo de tales condiciones que Celestina, contemplándolo desnudo, puede exclamar que «no paresce que ayas quinze años» (VII, p. 202) es, sin embargo, una "marcada ramera», o sea, es de una clase de prostitución que indica que ella la debe ejercer apartada de los prostíbulos establecidos y controlados. Así que puede vivir en casa propia ${ }^{16}$, y la tiene pagada por un protector. Su protector de momento es un señor militar, sin embargo, «que se partió ayer con su capitán a la guerra» (VII, p. 203). Areúsa sigue en contacto también con un protector o rufián de antes, Centurio, a quien -aprendemos- ella terminó protegiendo y subvencionando, pero inútilmente ${ }^{17}$.

\section{5.- La voz «pastelera» también tiene matices de prostituta.}

16.- En la casa de Areúsa entramos en el auto VII. En el auto IX, al final de su filíicica en contra de las señoras que tratan mal a sus criadas, termina orgullosamente Areúsa exclamando ante Celestina: "Por esto, madre, he querido más bivir en mi pequeña casa esenta y señora, que no en sus ricos palacios sojuzgada y cativa» (p. 233, énfasis añadido). Su relación con Centurio, sin embargo, nos permite ver que hay sentidas contradicciones en su noción de independencia (cf. Jerry R. Rank, "Awareness and Reaction: The Underlying Elements of Characterization of the Servants in Celestina», Kentucky Romance Quarterly, 19 [1972], pp. 223-36).

17.- «Vete de mi casa, rufián, vellaco [...] que me traes engañada, bova, con tus ofertas vanas [...] asme robado quanto tengo. Yo te di, vellaco, sayo y capa, spada y broquel, camisas de dos en dos a las mil maravillas labradas; yo te di armas y cavallo [...]. Agora una cosa que te pido que por mí hagas, pónesme mil achaques» (xv, p. 294). De estas palabras, se deduce 
Esta ramera no puede tener, desde luego, los «quinze años» mencionados por Celestina, pero siendo "prima» de Lucrecia, con unos dieciséis o diecisiete, y «prima» de Elicia, con unos veintipocos, estimo que Areúsa no debe sobrepasar los veintidós o veintitrés. Ella es la envidia de todos, como reconoce Celestina en el auto vil y Sosia en el auto XVII: «[N]inguno habla en loor de hermosas que primero no se acuerde de ti que de quantas son» (p. 309) ${ }^{18}$.

Dato curioso es que desde la casa de Calisto se puede ver la casa en la que vive Areúsa (XIV, p. 293). Está o en la misma calle, o en otra perpendicular a ella. Pero la distancia no es grande, porque Sosia - desde la ventana de la casa de Calisto con Tristán- puede identificar a una conocida suya, Elicia ${ }^{19}$, ahora enlutada, entrando en la casa de Areúsa, ésta una «mujer muy fresca y graciosa, enamorada, medio ramera ${ }^{20}$ ». Lo que ninguno de estos criados puede sospechar en este momento es que Areúsa, momentos después, estará planificando -irónicamente- la seducción de Sosia con la colaboración de Elicia. Esta proximidad de las casas de Calisto y Areúsa parece poco tomada en cuenta por Calisto en el texto, pero sí ocasiona sendos comentarios interesantes tanto de Celestina como de Areúsa.

En el auto vil, es la tercera que habla de esto al decir a Areúsa: «Pármeno y él [Sempronio] son compañeros, sirven a este señor [Calisto] que tú conoçes, y por quien tanto favor podrás tener» (p. 204, énfasis añadido). Y es por estas palabras que sabemos que Areúsa conoce a su vecino, Calisto. Hay confirmación de esta cercanía visual de Calisto y Areúsa en boca de la ramera en el auto IX, cuando se alía con Elicia en la denigración de la «gentil» Melibea que les ha provocado Sempronio: «No sé qué se ha visto Calisto porque dexa de mirar otras que más ligeramente podría aver y con quién más holgasse» (p. 228, énfasis añadido). Areúsa no hace aquí una ligera observación filosófica sus palabras son profundamente interesadas. Parece claro ahora, si no antes, la noción de Celestina de que estos dos -Calisto y Areúsa (recordemos que son vecinos y se verían con cierta frecuencia)— podrían llegar a más. Areúsa ha visto a Calisto como cliente

también que Areúsa dispone de bastante dinero, en contraste con sus «primas», Elicia y Lucrecia, económicamente más marginadas.

18.- Tal vez esta superioridad que puede sentir Areúsa — con tantos elogios de hombre y de mujeres- es lo que intensifica su desdén para con Melibea y su incomprensión de la atracción que siente Calisto por ella.

19.- Elicia también conoce a Sosia. Dice a Areúsa: «Yo conozco, amiga, otro compañero de Pármeno, moço de cavallos, que se llama Sosia [... ]» (xv, p. 299). Luego, comenta Sosia a Tristán: "[Areúsa] embióme a Elicia, rogándome que la visitasse [...]» (xIX, p. 318). La crítica ha notado poco esta amistad como vínculo en la cadena de sucesos que producen la tragedia final (de la versión en veintiún autos).

20.- Es probablemente la misma ventana de la primera planta de la casa desde donde vio Pármeno acercarse a Sempronio y Celestina en el auto I, una que ofrece la posibilidad de ver a cierta distancia todo lo que ocurre. 
-o compañero- sexual y ahora expresa fuertes celos desdeñando a Melibea ${ }^{21}$, viéndose como una de las "otras» que Calisto, con menos empeño, podría tener. Con esta atracción manifiesta para Calisto, y estos celos a flor de boca, podemos llegar a entender mejor el odio que tiene Areúsa a los amantes cuando manda al sicario que acaba de contratar: "Centurio, da buena cuenta de lo encomendado; de cualquier muerte holgaremos» (xvili, p. 317, énfasis añadido).

No nos debe sorprender el hecho de que una "marcada ramera», Areúsa, viva en el buen barrio de Calisto, siendo que Celestina, hace poco, vivió cuatro años en el barrio de Pleberio. Areúsa, siendo más independiente y no perteneciendo a ningún burdel, que estaban normalmente situados en los arrabales urbanos, puede vivir donde quiera ${ }^{22}$.

\section{Lucrecia y Elicia, primas}

Hay tres indicaciones textuales - todas ellas presentes en la versión de dieciséis autos- de un posible parentesco entre estas mujeres, dos en el auto IV y la tercera en el auto IX. Al acercarse Celestina a la casa de Pleberio al comienzo del auto Iv, vacila en su propósito por un ataque de nervios o dudas, pero se siente reconfortada por varios agüeros positivos que encuentra por el camino y por ver a la puerta a Lucrecia, y los ánimos de Celestina suben cuando murmura entre dientes: «Prima es de Elicia; no me será contraria» (p. 151). Y aunque en el texto Elicia no ha dicho nada de esto a Celestina, ésta saluda a Lucrecia alegando, entre otras cosas: «Hija, mi amor, desseo de todos vosotros traerte encomiendas de Elicia» (p. 151). Se asume que Lucrecia aceptará este saludo de su prima, aunque no lo devuelve. Parece cierta que la nueva confianza que siente Celestina al ver a una que, por estar emparentada con la Elicia que vive con ella, no sea una ficción de un parentesco, sino un parentesco sólido, verdadero.

Más tarde, será Elicia misma, antes de ver a la persona que llama a la puerta de Celestina en el auto IX, quien adivina quién es: «la boz me

21.- Areúsa conoce también, al menos de vista, a la nueva amante de Calisto. Después de dejar a Melibea malparada Elicia, Areúsa se dirige a su prima y colega: "Pues no la has tú visto como yo, hermana mía» (IX, p. 226, énfasis añadido). En lo siguiente, el desprecio de la ramera para con la dama se manifiesta no sólo en el sentido de las diferencias de clase social, sino en su igualdad como mujeres y hasta como seres humanos, una actitud expresada a menudo por Areúsa como, por ejemplo, en su famosa declaración del auto IX: «[...] las obras hazen linaje; que al fin todos somos hijos de Adam y Eva. Procure de ser cada uno bueno por sí, y no vaya a buscar en la nobleza de sus pasados la virtud» (p. 229).

22.- Se puede creer que la mudanza de Celestina ha sido tan reciente porque las autoridades ya no podían hacer la vista gorda de sus actividades — aunque quisieran — en el mercado carnal, antes tan bien cubiertas por sus otros oficios, seis en el testimonio de Pármeno (I, p. 110) y treinta en la más hiperbólica frase de Lucrecia (Iv, p. 152). 
engaña, o es mi prima Lucrecia» (p. 232, énfasis añadido) ${ }^{23}$. Y luego Celestina, en el mismo auto, dirigiéndose a Lucrecia, dirá: «Yo vi, mi amor, a esta mesa donde agora están tus primas assentadas [...]» (p. 234, énfasis añadido), refiriéndose a Elicia y Areúsa. Lo más llamativo puede ser que Lucrecia nunca menciona su deudo con Elicia. Pero si tanto Celestina como Elicia se sienten contentas con declarar que Lucrecia es prima de la pupila de nuestra alcahueta, y Lucrecia no ha entrado en el círculo de la prostitución, en el cual el término "prima» significa la hermandad profesional, no veo razón alguna para dudar que entre Lucrecia y Elicia exista un parentesco de sangre.

\section{Lucrecia y Areúsa, primas}

La única referencia textual a éstas dos como primas ocurre en el auto IX, p. 234, cuando Celestina, dirigiéndose a Lucrecia, dice: «Yo vi, mi amor, a esta mesa donde agora están tus primas assentadas [...]» (p. 234), refiriéndose a Elicia y Areúsa. Lo sorprendente es que en ningún momento del texto tampoco Lucrecia misma haga referencia a Areúsa como prima suya. Areúsa tampoco. Es sólo Celestina quien lo señala ${ }^{24}$. Quede por el momento en el aire el posible parentesco de sangre entre éstas dos.

\section{Elicia y Areúsa, primas}

Son "primas» de profesión, esto va sin decir, pero otra posible conclusión es que realmente lo son. Por eso, antes de detallar las menciones textuales, primero creo necesario subrayar enfáticamente lo que dice Celestina a Areúsa en el auto vII:

Ya sabes el deudo que ay entre ti y Elicia, la qual tiene Sempronio en mi casa. Pármeno y él son compañeros, sirven a este señor que tú conoces, y por quien tanto fa-

23.- Curiosamente, Lucrecia reconoce la voz de Calisto al comienzo del auto XII antes de verlo. Melibea manda a Lucrecia: «Loca habla, passo; mira bien si es él». Y contesta Lucrecia: "Allégate, señora, que sí es, que yo le conozco en la boz» (p. 259, énfasis añadido). Es realmente curioso aprender que todas estas primas conocen a Calisto desde antes del comienzo de la acción de la obra, a pesar de que a veces el lector no lo nota en su primera lectura. Como Sempronio es criado de Calisto, Elicia le debe conocer desde hace tiempo, y a Areúsa le interesa para el sexo, como ya hemos observado (auto viI, p. 204; auto IX, p. 228).

24.- Reconozco que me pasé por alto esta confirmación de Celestina en lo que escribí en "Lo teatral en Celestina: el caso de Areúsa", Proceedings of the International Congress in Commemoration of the Quincentennial Anniversary of 'La Celestina', ed. O. Di Camillo, New York, Hispanic Society of America/CUNY Graduate Center, 2005, pp. 207-217. 
vor podrás tener $[\ldots]$ vosotras parientas, ellos compañeros, mira cómo mejor medido que lo queremos (p. 204).

Hay "deudo» entre ellas, y son "parientas», además de alistadas en la misma profesión como «primas». ¿No es posible, entonces, que éstas dos, siendo de veras parientas con un deudo entre ellas reconocido como tal, y también siendo prostitutas, sean "primas» por los dos lados? Pero sigamos con esta línea de investigación textual.

Además de lo dicho por Celestina, llevan muchos años conociéndose. Elicia, Areúsa dixit (xv, p. 299), bien conoció a la madre pastellera de Areúsa $\mathrm{y}$, sin duda, a Eliso, su padre. Hemos de reconocer que su relación comienza mucho antes del comienzo de la acción textual. Esto aceptado, es lógico creer que Areúsa conoce a la abuela de Elicia, especialmente porque eran de la misma profesión. Y si Areúsa y Elicia son primas por parentesco de sangre - como sostiene Celestina- esto hace que la pastelera vieja (ya muerta) y su marido, Eliso, los padres de Areúsa, sean también tíos de Elicia. Hace que Areúsa también sea parienta de la abuela de Elicia. Y como Lucrecia es prima verdadera de Elicia, todos estos antepasados "invisibles» del texto celestinesco formarán parte de una familia extendida de las tres primas que estamos intentando elaborar en estas páginas ${ }^{25}$.

Volvamos a Elicia y Areúsa: en los autos IX, XV, XVII, y XVIII, conversan las dos, tildándose no sólo de "primas» (IX, p. 224; XV, pp. 294, 296, 300; XVII, pp. 308, 312; XVIII, p. 314), sino también de "hermanas» (IX, pp. 226, 229; XV, pp. 295, 296, 298; XVII, pp. 307, 308, 309; XVIII, pp. 313, 316 y 317) y con otros términos cariñosos no muy usuales entre competidores en el mercado carnal, como «amiga» (xv, p. 296), "alma mía» (xv, p. 299) y «sabia mujer» (XVII, p. 312). Las dos intercambian libremente estas designaciones.

La primera mención textual de este parentesco lo vimos en auto I, cuando Celestina, ya habiendo hablado con Pármeno de Areúsa, le estimula así: "¡O si quisiéssedes, Pármeno, que vida gozaríamos! Sempronio ama a Elicia, prima de Areúsa...» (p. 124) ${ }^{26}$. Y de este parentesco hemos visto arriba cuánta ventaja hace Celestina en el auto VII. Pero este parentesco será Sempronio quien luego volverá a mencionarlo.

Ocurre en el auto viII, hablando Sempronio con un desbordado Pármeno, recién llegado de su larga noche de amores con Areúsa. Casi no lo puede creer Sempronio, exclamando: "Pero, por Dios, me digas qué es esso que dixiste de Areúsa. Parece que conoçes tú a Areúsa su prima de

25.- Manejo el término «invisible» en el sentido usado por A. Deyermond en su estudio "How Many Sisters Had Celestina? The Function of the Invisible Characters», Celestinesca, 21 (1997), pp. 15-29.

26.- Celestina, sin mencionar el parentesco, le recordará a Sempronio, cuando éste le pregunta cómo piensa cambiar la declarada oposición de Pármeno, que «Haréle aver a Areúsa, será uno de los nuestros» (III, p. 143). 
Elicia» (p. 215, énfasis añadido). Y cuando Pármeno habla elogiosamente de las gracias de su habla y de su cuerpo, Sempronio se declara convencido: "¿Puede ser sino prima de Elicia? [...]. Todo te lo creo» (p. 216, énfasis añadido $)^{27}$.

Me parece que esta insistencia de Sempronio tiende a confirmar que, más que ser las "primas» de profesión que son, Elicia y Areúsa son primas de deudo. Celestina, como ya vimos, confirmará este deudo y parentesco en el auto Ix. Cuando Elicia, furiosa por el elogio que de Melibea hizo Sempronio, le dice que ella, cuando Semponio se ausenta, está ya con otro, Celestina quiere amainar la tensión y dice a Sempronio:

Hijo, déxale dezir, que devanea; mientra más de esso la oyeres, más se confirma en su amor. Todo es porque avés aquí alabado a Melibea; no sabe en otra cosa que os lo pagar sino en dezir esso [...]. Pues essotra su prima [Areúsa] yo [me] la conozco; gozad vuestras frescas mocedades [...] (p. 231, énfasis añadido).

Esta nueva referencia a Areúsa, como prima de Elicia, llega a ser tan obsesiva en el texto que ya no dudamos de que sea este parentesco uno real y que son, efectivamente, primas de sangre éstas dos. Siendo prima de sangre Lucrecia de Elicia, no queda ahora más remedio que aceptar, aun con pocas citas textuales, el parentesco entre Lucrecia y la mayor de las tres primas, Areúsa.

\section{Conclusiones, y algo sobre el tema de linajes}

Me es evidente que el texto celestinesco tiene muchos recovecos que uno descubre con cada lectura nueva que se haga ${ }^{28}$. Con estos nuevos detalles se va cambiando nuestra perspectiva y ahondamos más en el complejo mundo no sólo en la obra sino en el mundo que rodea la obra y le confiere buena parte de su vitalidad. Aquí hemos intentado ver más hondo en el texto de Celestina - tratando el tema de las tres primas-y hemos podido ver que cada una de las tres tiene una historia como individuo con sus circunstancias particulares, pero que también tiene unas vivencias que se entrelazan con las de las otras primas, y con más per-

27.- A lo largo de obra, no sólo aquí, Sempronio presume de su amor por Elicia. Él dirá en el auto IX: «...aquí está quien me causó algún tiempo andar fecho otro Calisto» (p. 231), refiriéndose a Elicia. Es un hecho reconocido también por Sosia, describiéndola: «aquella es Elicia [...] queda agora perdida la peccadora porque tenía a Celestina por madre y a Sempronio por el principal de sus amigos» (XIV, p. 293, énfasis añadido).

28.- En esto sigo las huellas del autor de la Carta a un su amigo que volvió a leer el texto delante tres o cuatro veces, siempre viendo nuevas cosas que le hacía profundizar sus ideas y ejercer cada vez más su memoria de las previas lecturas, agrandándolas significativamente. 
sonajes «invisibles» de la obra (mencionados pero no presentes) y todos ellos resultan ser miembros de una familia extendida de profesionales del mundo de la prostitución, ahora liderada por la vieja Celestina. Así que el autor de esta obra tuvo a bien presentar a sus tres anti-heroínas con su pasado y su presente, dejándolas vivas para un futuro no contado, si bien está implícito.

Pero finalmente se confirma mi sospecha inicial de que las tres son, de veras, primas de sangre, además de estar cada una en distintas fases del trayecto de una vida profesional que las une o las unirá. Su estado social inferior o marginado, sin embargo, no les priva de mantener interés como individuos con tanta historia como los personajes de más alcurnia en Celestina.

Lucrecia es, al comienzo de Celestina, vista como criada de buena familia, pero sus deseos libidinosos se ven a flor de boca al ver a su señora tan rendida ante los amores de Calisto y es más que probable que dentro de poco estará Lucrecia siguiendo los pasos sensuales ya dados públicamente por sus dos primas -y en privado por su señora. Elicia lleva ya unos años en el burdel de Celestina y aunque Sempronio es el "principal de sus amigos» (XIV, p. 293), no parece pagar nunca sus servicios, ella y Celestina cobran de los que, como Crito y sus congéneres, pagan liberalmente sus servicios como clientes. La hermosura de la tercera del trío, Areúsa, está en boca de todos y ella ha llegado al servicio de un solo protector, viviendo en casa pagada y no obligada a complacer gustos de una pluralidad de clientes. Estas tres primas representan en miniatura el gran panorama del mundo prostibulario, desde fuera (Lucrecia) y desde dentro (Elicia, Areúsa).

Melibea tiene dos padres de la alta burguesía. Calisto los tenía también (de "claro linaje», xx, p. 333) pero están ya muertos al comienzo de la acción. Se mencionan dos de sus abuelos también, aunque en circunstancias mucho menos nobles (I, p. 96). A las tres primas, de una clase social menos particularizada en las letras castellanas hasta la fecha, también el autor de Celestina les concede su linaje, y podríamos vislumbrar en todas estas referencias un intento de burla irónica al dar tanto relieve al linaje de nuestras tres primas como a los miembros del estado social privilegiado.

Hay más burla irónica si contrastamos el comportamiento de los dos amantes nobles que participan en sus deseos ilícitos ${ }^{29}$ con el mismo sensualismo urgente -y hasta brusco- de Pármeno con Areúsa (autos VII, IX) y Sempronio con Elicia (autos III, IX). Y no dejemos fuera los deseos frustrados de una Lucrecia que se negará a rogar a los criados de Calisto (Tristán, Sosia, éste que ya es amigo de ella [XIX, p. 324]). Pero estas tres parejas comparten el mismo rechazo como marginados sociales.

29.- Que sea ilícito es reconocido desde luego desde la primera escena de la obra, en palabras de la asustada a la vez que fascinada Melibea: «...que no puede mi paciencia tolerar que haya subido en corazón humano conmigo el ilícito amor comunicar su deleyte» (I, p. 87, énfasis añadido). 
Son distintos los dos casos de (1) una meretriz (Areúsa) que aspira a contentar a Calisto y (2) el evidente deseo de Sempronio ante la hermosura de Melibea ${ }^{30}$, donde las líneas o barreras entre las clases se cruzan, por lo menos en la imaginación. Con esto último, vemos, sin embargo, que en Celestina la noción tradicional de linajes está revesada y rebasada, revelando - a mi juicio - que el autor pensaba que la descendencia por linajes no vale como factor realmente importante en la construcción de la vida, sino como mero accidente, como circunstancia sobre la que nadie ejerce control. Como dice con gran contundencia una animosa Areúsa: "Ruyn sea quien por ruyn se tiene; las obras hazen linaje, que al fin todos somos hijos de Adam y Eva» (IX, p. 229, énfasis añadido).

En los albores del Renacimiento y de la revaloración menos jerárquica de los individuos que componían las esferas sociales, podemos ver que la presentación y caracterización de las tres primas del entorno celestinesco representa un avance hacia el futuro y un señalado distanciamiento de los valores institucionalizados de la Baja Edad Media.

\section{Bibliografía citada}

ABRIL-SÁnCHEZ, Jorge, "Una familia de meretrices: prostitutas públicas y privadas, cortesanas, rameras y putas viejas en la Celestina», Celestinesca, 27 (2003), pp. 7-24.

CARRASCO, Félix, "Diálogo, antidiálogo y conciencia de clase en La Celestina», Imprevue. Idéologie et practiques discursives, Imprévue, Montpellier, CERS, 1979, pp. 103-18.

CASAlDUERO, Joaquín, «Parodia de un cuestión de amor y queja de las fregonas», Revista de filología española, 19 (1932), pp. 181-87.

CiplifausKaITÉ, Biruté, "Juegos de duplicación e inversión en La Celestina", en Homenaje a José Manuel Blecua, Madrid, Gredos, 1983, pp.165-73.

Del Barrio, Florencio, «Los términos de parentesco como formas de tratamiento en La Celestina», Anuario de Lingüística Hispánica, 19-20 (2004), pp. 201-226.

DeYermond, Alan, «How Many Sisters Had Celestina? The Function of the Invisible Characters», Celestinesca, 21 (1997), pp. 15-29.

30.- Después de conseguir el cordón de Melibea, Celestina se encuentra en la calle con Sempronio, cuya curiosidad de saber lo que pasó con Melibea hace que la astuta alcahueta vea lo que anima más al criado de Calisto: «Yo lo veo en ti que querrías estar más al sabor que al olor deste negocio» (v, p. 175, énfasis añadido). 
Eaton, Catherine, "The Character of Lucrecia in La Celestina», Annali dell'Istituto Orientale-Sezione Romanza, 15 (1973), pp. 213-25.

ECHEVerRía, Gloria, «Lucrecia. Personaje secundario en la Celestina». Tesina: University of Georgia, 1991.

GERDAY, Jacqueline, "Le caractère des rameras dans La Célestine», Revue des Langues Vivantes, 33 (1967), pp. 185-204.

Godoy-Barde, Pierrette, "Tristan, Sosie et Lucrece face au secret», Les langues neo-latines 90.3 (1996), n. 298, pp. 147-52.

Hathaway, Robert, “Fernando de Rojas' Pessimism: The Four Stages of Life for Women at the Margin», Celestinesca, 18.2 (1994), pp. 53-73.

Lida de Malkiel, M. Rosa, La originalidad artística de 'La Celestina', Buenos Aires, EUDEBA, 1962.

MuÑoz GarRIgós, José, "Andar a pares los diez mandamientos: Un pasaje oscuro de La Celestina», en Homenaje a Prof. Muñoz Cortés, Murcia, Universidad, 1976, t.I, pp. 437-446.

Oramura, Jaime, "Lucrecia en el esquema didáctico de Celestina», Celestinesca, 15.1 (1991), pp. 53-62.

Rank, Jerry R., "Awareness and Reaction: The Underlying Elements of Characterization of the Servants in Celestina», Kentucky Romance Quarterly, 19 (1972), pp. 223-36.

Segura Graíño, Cristina, "Las mujeres en La Celestina», en Feminismo y misoginia en la literatura española, ed. C. Segura Graíño, Madrid, Nancea, 2001, pp. 47-58.

Swietlicki, Catherine, 1985. «Rojas' View of Women: A Reanalysis of La Celestina», Hispanófila, 85 (1985), pp. 1-13.

TAPia, María Cruz Muriel, Antifeminismo y subestimación de la mujer en la literatura medieval castellana, Cáceres, Guadiloba, 1991.

Weber, Alison P., "Celestina and the Discourses of Servitude", in Negotiating Past and Present. Studies in Spanish Literature for Javier Herrero, ed. David T. Gies, Charlottesville, VA, Rockwood Press, 1997, pp. 127-144. 
SNOW, Joseph E., "Las tres primas del entorno celestinesco y una nota sobre el tema del linaje», Celestinesca 32 (2008), pp. 291-305.

\section{RESUMEN}

Este estudio pretende escudriñar el texto celestinesco para reunir toda la evidencia relevante al probable parentesco real entre Elicia, Areusa, y Lucrecia, las «tres primas». Esta documentado que 'prima' era un termino afectuoso entre las mujeres trabajando en la prostitución: en Celestina, sin embargo, sin excluir ese sentido al referirse a las tres mujeres estudiadas, parece demostrable que un verdadero parentesco de sangre une a las tres.

PALABRAS ClaVE: linaje, parentesco, primas, prostitucion, Elicia, Areusa, Lucrecia.

\section{ABSTRACT}

This study aims to scrutinize the Celestina text to collect all relevant information about the relationship of three young women: Elicia, Areusa, and Lucrecia. Although it is well documented that the term 'prima' (cousin) was common among prostitutes as a term of sisterly affection, it appears that in Celestina the three women are truly cousins, related by bloodlines rather than solely by professional association.

KEY WORDS: lineage, kinship, cousins, prostitution, Elicia, Areusa, Lucrecia.

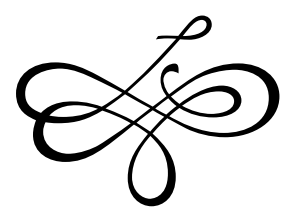

